\title{
Patterns of linkage disequilibrium and association mapping in diploid alfalfa (M. sativa $\mathrm{L}$.)
}

\author{
Muhammet Sakiroglu • Sue Sherman-Broyles • \\ Alec Story $\cdot$ Kenneth J. Moore $\cdot$ Jeffery J. Doyle $\cdot$ \\ E. Charles Brummer
}

Received: 28 September 2011 / Accepted: 10 March 2012 / Published online: 5 April 2012

(C) The Author(s) 2012. This article is published with open access at Springerlink.com

\begin{abstract}
Association mapping enables the detection of marker-trait associations in unstructured populations by taking advantage of historical linkage disequilibrium (LD) that exists between a marker and the true causative polymorphism of the trait phenotype. Our first objective was to understand the pattern of LD decay in the diploid alfalfa genome. We used 89 highly polymorphic SSR loci in 374 unimproved diploid alfalfa (Medicago sativa $\mathrm{L}$.) genotypes from 120 accessions to infer chromosome-wide patterns of LD. We also sequenced four lignin biosynthesis candidate genes (caffeoyl-CoA 3-O-methyltransferase (CCoAoMT), ferulate-5-hydroxylase (F5H), caffeic acid-O-methyltransferase (COMT), and phenylalanine amonialyase (PAL 1)) to identify single nucleotide polymorphisms (SNPs) and
\end{abstract}

Communicated by J. Yan.

M. Sakiroglu and S. Sherman-Broyles contributed equally

Electronic supplementary material The online version of this article (doi:10.1007/s00122-012-1854-2) contains supplementary material, which is available to authorized users.

M. Sakiroglu

Department of Bioengineering, Kafkas University,

Kars 36100, Turkey

S. Sherman-Broyles · A. Story $\cdot$ J. J. Doyle

Department of Plant Biology, Cornell University,

Ithaca, NY 14853, USA

K. J. Moore

Department of Agronomy, Iowa State University,

Ames, IA 50011, USA

E. Charles Brummer ( $\square)$

Samuel Roberts Noble Foundation,

2510 Sam Noble Parkway, Ardmore, OK 73401, USA

e-mail: ecbrummer@noble.org infer within gene estimates of LD. As the second objective of this study, we conducted association mapping for cell wall components and agronomic traits using the SSR markers and SNPs from the four candidate genes. We found very little LD among SSR markers implying limited value for genomewide association studies. In contrast, within gene LD decayed within $300 \mathrm{bp}$ below an $r^{2}$ of 0.2 in three of four candidate genes. We identified one SSR and two highly significant SNPs associated with biomass yield. Based on our results, focusing association mapping on candidate gene sequences will be necessary until a dense set of genome-wide markers is available for alfalfa.

\section{Introduction}

Linking DNA polymorphism to trait phenotypic variation is an increasingly important tool for plant breeding programs (Lande and Thompson 1990). Historically, segregating populations of a particular cross have been used to identify marker-trait associations (e.g., Stuber et al. 1999). More recently, association mapping has shown promise for trait mapping due to the increased access to abundant molecular markers in many crops (Stich et al. 2005).

Association mapping takes advantage of the fact that historical recombination within a population has decreased linkage disequilibrium (LD) to short chromosomal intervals, enabling potentially statistically strong and robust marker-trait associations to be detected (Jannink and Walsh 2002). In association mapping, existing allele variation within an entire population can be more efficiently represented because mapping is conducted directly in breeding populations (Hirschhorn and Daly 2005; Remington et al. 2001). In general, the precision of locating a QTL is much higher in association panels compared to biparental 
mapping populations, provided sufficient markers are available to detect the QTL. If LD extends over long distances, however, the biparental mapping approach is more powerful to detect the existence of a QTL, particularly if marker numbers are limited (Mackay and Powell 2007).

Two major drawbacks exist in association mapping. First, false positive associations between markers and traits can be obtained due to the presence of population structure (Aranzana et al. 2005; Lander and Schork 1994). However, population structure can be assessed with marker information from genome-wide genetic markers (such as SSRs), and association tests can then be conditioned on the population structure to reduce the false positive rate (Aranzana et al. 2005; Pritchard et al. 2000). Second, the extent of LD plays a practical role in determining the number of markers needed to detect associations between genotype and phenotype (Rafalski and Morgante 2004). Limited LD in the population means that associations will only be detected between alleles at loci close together, requiring many markers to saturate the genome (Hagenblad and Nordborg 2002). When the limiting factor for association mapping is the absence of a sufficiently large number of markers evenly dispersed throughout the genome, an alternative strategy is to assay variation in candidate genes (Neale and Savolainen 2004). For both cases, the design and use of association studies require knowledge of the LD structure in the genome (Oraguzie et al. 2007).

Alfalfa is one of the most important forage legumes in the world (Quiros and Bauchan 1988; Michaud et al. 1988), and has been proposed as a bioenergy crop (Delong et al. 1995). Alfalfa has potential to produce high yield but genetic improvement for yield is not as high as has been realized for the major grain crops (Hill et al. 1988). Digestion of forage for animal nutrition or for cellulosic bioethanol production requires the effective hydrolysis of cellulose and solubilization of hemicellulose in the presence of lignin (U.S. DOE 2006). Reducing lignin content can increase the efficiency of sugar release from cell wall complexes up to two fold (Chen and Dixon 2007). Therefore, improving biomass yield and modifying the plant's cell wall composition are two breeding targets important for both forage and biofeedstock (Ragauskas et al. 2006) applications. If QTL associated with yield and cell wall components could be identified, they could be incorporated into modern cultivars enhancing the efficiency of alfalfa breeding.

Cultivated alfalfa is an autotetraploid $(2 n=4 \mathrm{x}=32)$ domesticated from the Medicago sativa-falcata complex. Autotetraploidy complicates genetic mapping, but diploid $(2 n=2 \mathrm{x}=16)$ relatives of alfalfa exist that share the same karyotype, have highly syntenic genetic linkage groups, and can be hybridized with tetraploid individuals (Diwan et al. 2000; McCoy and Bingham 1988; Quiros and Bauchan 1988). The diploid members of the complex include M. sativa subsp. falcata, M. sativa subsp. caerulea, and their natural hybrid, M. sativa subsp. hemicycla (Quiros and Bauchan 1988; Havananda et al. 2010).

The genomewide extent of LD in the M. sativa-falcata complex has previously been estimated in one tetraploid breeding population using SSR markers ( $\mathrm{Li}$ et al. 2011). Within gene LD was estimated in a set of different tetraploid breeding populations using two regions of the alfalfa gene homologous to M. truncatula CONSTANS-LIKE gene (Herrmann et al. 2010). However, both of these populations are expected to have had reduced recombination due to breeding efforts compared to a broad-based natural population. In this paper, we assess both chromosome-wide estimates of LD in a population consisting of 374 unimproved diploid alfalfa genotypes from 120 accessions using 89 polymorphic SSR loci distributed throughout genome and within gene estimates of $\mathrm{LD}$ in sequences of four candidate genes of the lignin biosynthesis pathway. In addition, we evaluated SSR and candidate gene SNP marker polymorphisms for associations with 23 traits relevant to biomass accumulation and cell wall components.

\section{Materials and methods}

Plant materials and phenotyping

We selected 374 individual genotypes from 120 accessions obtained from the USDA National Plant Germplasm System, representing the geographical distribution of the diploid M. sativa complex, including subsp. caerulea, falcata, and hemicycla (Supplemental Table 1) (Sakiroglu et al. 2010; Sakiroglu and Brummer 2011). These genotypes were planted in field experiments near Watkinsville and Eatonton, Georgia. The experimental design and procedures were reported previously (Sakiroglu et al. 2011). We evaluated neutral detergent fiber (NDF), acid detergent fiber (ADF) acid detergent lignin (ADL), and total nonstructural carbohydrate (TNC) composition, glucose, xylose, arabinose, total aboveground biomass yield, and regrowth after harvest in 2007 and 2008. Five other agronomic traits were measured in 1 year, stem yield and stem/ leaf ratio in 2007, and plant height, stem thickness, and spring regrowth in 2008 (Sakiroglu et al. 2011).

\section{Genotyping and sequencing}

We scored 89 SSR loci on the 374 genotypes and analyzed genetic relationships among them, as described previously (Sakiroglu et al. 2010). The putative physical location of the SSR markers was determined using BLAST to find the sequence of the SSR primers or the EST from which the SSR marker was developed on the genome sequence of M. truncatula, version 3.5.1 (www.medicago.org) (Fig. 1). 

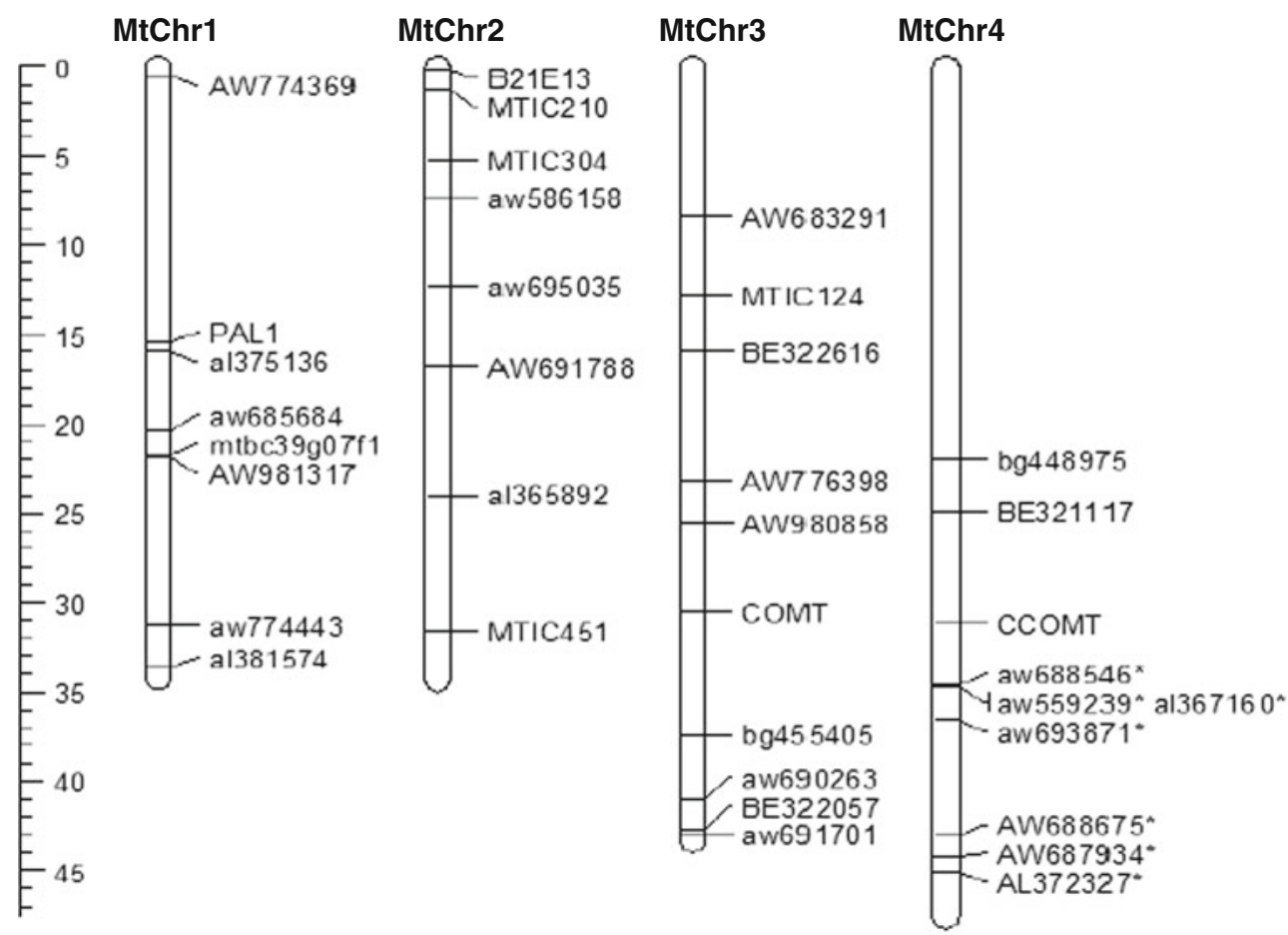

\section{MtChr5}

\section{MtChr6}

MtChr7
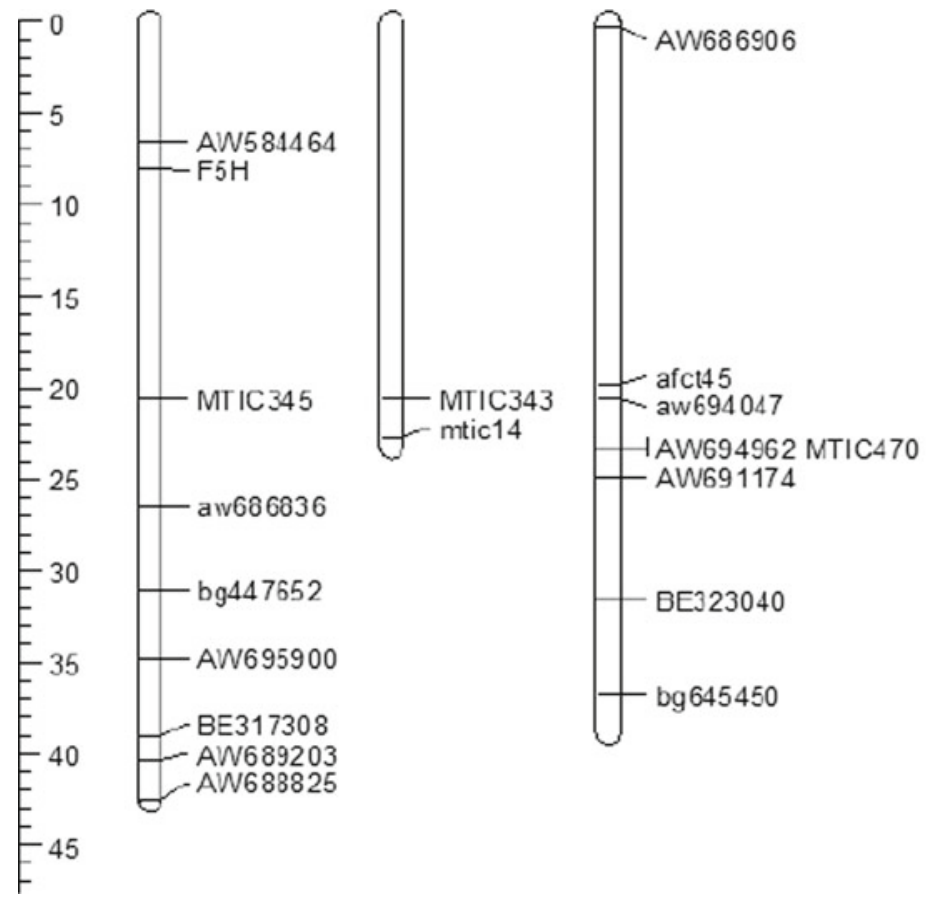

MtChr8

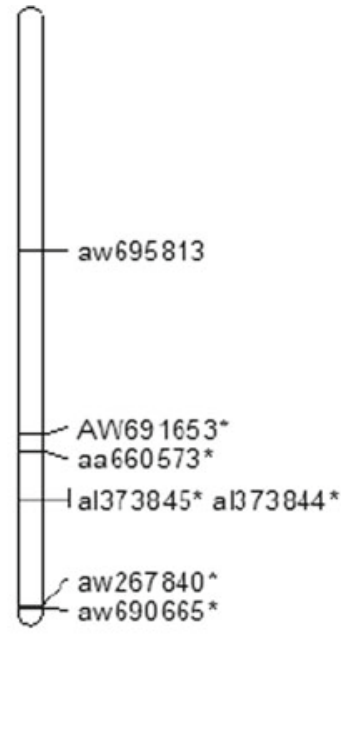

Fig. 1 Physical locations of 58 of 89 SSR markers and four candidate genes on Medicago truncatula chromosomes, Mt genome sequence version 3.5.1. The ruler indicates scale in $\mathrm{Mb}$

We initially targeted to sample one individual from each of 72 accessions from the original 120 accessions for 454 amplicon resequencing (Meyer et al. 2008). However, we later discovered that the accessions denoted as PI 641380 and W6 4794 are a single accession. Therefore, we used 72 individuals from 71 accessions for candidate gene rese- quencing. We used the subset to ensure adequate sequence coverage of each heterozygous individual in our 454 library. The 71 accessions were selected to represent the subspecies throughout their geographic distribution and SSR marker cluster. We evaluated four genes in the lignin biosynthetic pathway as candidate loci associated 
with stem composition: caffeoyl-CoA 3-O-methyltransferase (CCoAoMT), ferulate-5-hydroxylase (F5H), caffeic acid-Omethyltransferase (COMT), and phenylalanine ammonialyase (PAL 1). Primers were designed to amplify fragments from these genes ranging in length from 289 to $645 \mathrm{bp}$. Contiguous fragments were overlapped by 77-327 bp to facilitate haplotype assignments (Supplemental Table 1). Three introns were not amplified presumably due to their excessive length (e.g., COMT has an intron greater than $5 \mathrm{~kb}$ in M. truncatula, which we assume is also large in alfalfa; Fig. 2) and were not included in the 454 library The DNA from 72 individuals was amplified using the Roche Fast Start High Fidelity PCR System (Roche, Branchburg, NJ, USA) following Meyer et al. (2008). Briefly, 30 cycles consisting of a $30 \mathrm{~s}$ denaturation step at $95^{\circ}, 30 \mathrm{~s}$ annealing step (temperature listed in Supplemental Table 2) and $30 \mathrm{~s}$ extension step at $72^{\circ}$, followed by a final 5 min extension at $72^{\circ}$. Products were visualized on agarose gels. In cases when amplification was weak, with PCR products faint or lacking on agarose gels, PCR products were diluted 1:5 and amplification was repeated using the same PCR conditions. All PCR products were reamplified from amplicons D, E, 15, F, F5H, 8, 9, and 10 (see Fig. 2). A subset of PCR products from amplicons e1f, B, C, 14, G, FQ61, and 13 was weak and therefore was reamplified. No products were reamplified from amplicon 7 . Amplicons from each individual were purified using AmPure SPRI beads (Beckman Coulter Genomics, Danvers, MA, USA) and quantified using the Picogreen Assay (Invitrogen, Carlsbad, CA, USA). All amplicons for each individual were pooled in equimolar concentrations and blunt end repaired prior to ligation of individual-specific tags. Tags consisted of eight
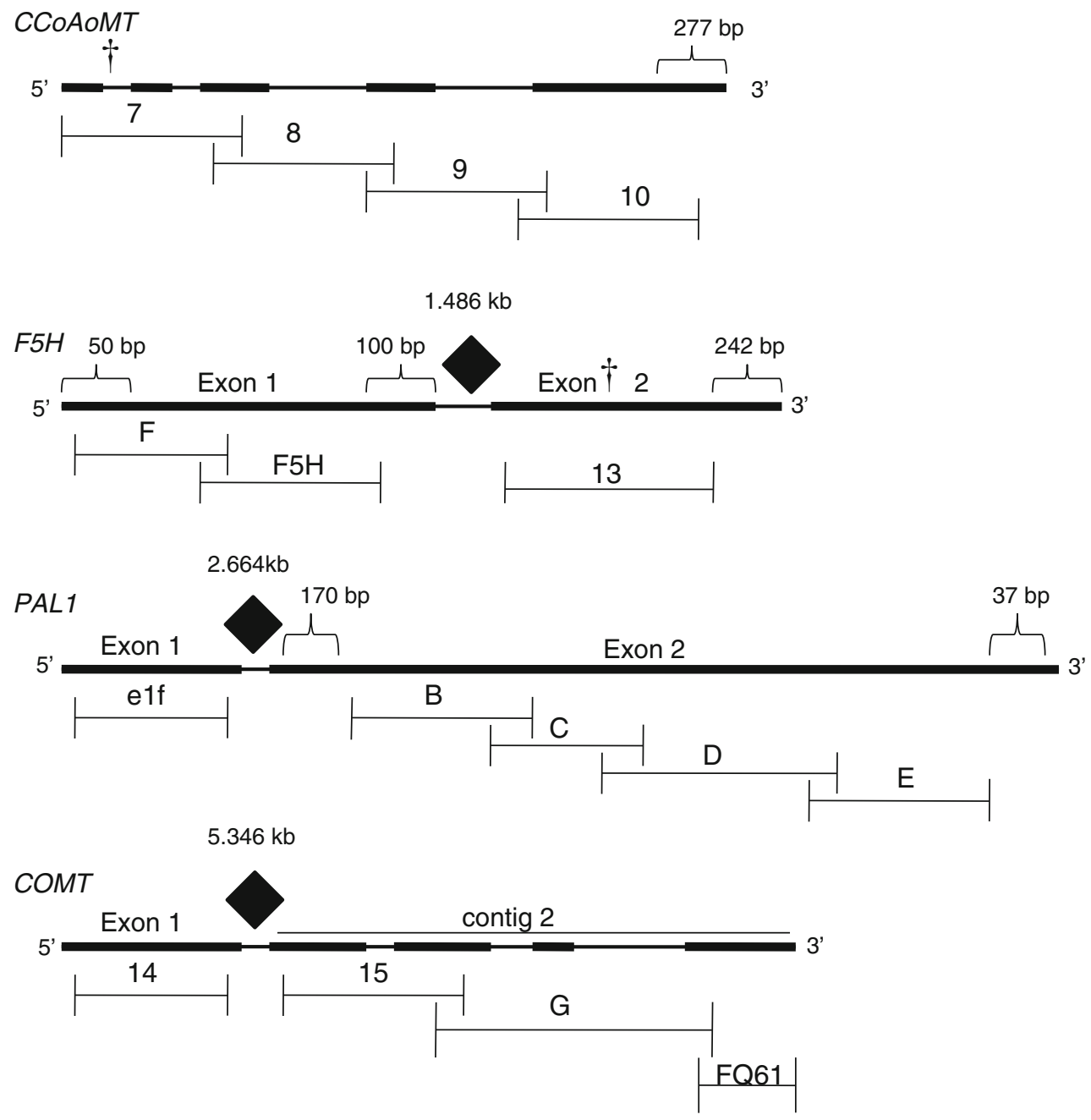

Fig. 2 Depiction of candidate genes with overlapping amplicons comprising seven contigs illustrated. Representation of four candidate genes and overlapping amplicons (length of amplicons in bp listed in Supplemental Table 1). Exons are rectangles. Brackets indicate the size of unsequenced gene. Three filled diamonds indicate introns and sizes determined from $M$. truncatula genome sequence that were not included in the sequencing. Dagger indicates location of SNPs significantly associated with biomass yield 
unique bases, a $\operatorname{Srfl}$ site and eight complementary bases forming a self annealing hairpin structure (Meyer et al. 2008). The tagged amplicons from each individual were pooled to form a single library. Dephosphorylation and digestion with $\operatorname{Srfl}$ of tags in the final pool, prior to ligation of library adapters, ensured that only tagged amplicons were sequenced. Roche/454 library preparation and sequencing were done by the Cornell University Life Sciences Core Laboratories Center using Roche 454 Genome Sequencer FLX instruments with Titanium chemistry (Roche Applied Science, Indianapolis, IN, USA) on half of a picotiter plate.

\section{Management of sequencing reads}

Sequences were sorted based on their tags using software provided at http://bioinf.eva.mpg.de/pts/ as described in Meyer et al. (2008), resulting in 72 FASTA files each representing the sequences from a single individual. Sequence reads were assembled for each individual using Lasergene's SeqMan program (DNASTAR, Madison, WI, USA) to produce seven contigs for each individual (Fig. 2). M. truncatula or $M$. sativa sequences used to design the primers for this project were added to each contig as a reference sequence. Each contig was exported from SeqMan as a phrap (.ace) file for use with an in-house Perl script. The script was written to determine single nucleotide polymorphisms (SNPs) and insertion-deletion polymorphisms (indels) within each contig by tallying the number of reads containing the same series of SNPs. Both SeqMan and our Perl script eliminated bases at low frequency $(<0.05)$, variation likely attributable to sequencing errors such as homopolymer regions.

Reamplification of PCR products led to a high rate of chimeric sequences due to recombination during the PCR. As a consequence, our script identified more than two haplotypes for each individual. The script identified the location of each SNP represented by an ambiguity code in the consensus sequence and the number of reads containing each SNP allele at each of those positions. SNP combinations with the highest frequencies, which we presumed were the non-chimeric sequences and replaced the IUPAC ambiguity codes in the consensus sequence to create two likely true haplotypes for each individual for $C C O A o M T$ and $F 5 H$. These manually determined haplotypes from $C C O A o M T$ and $F 5 H$ had similar LD plots as the LD analyses based on unphased SNP genotypes. Therefore, we used unphased SNP genotype data to estimate within gene LD as well as to conduct association tests. Manually determined haplotypes had slightly elevated diversity statistics for $C C O A o M T$ and slightly lower diversity statistics for $F 5 H$ (Supplemental Table 3) compared to haplotypes determined by PHASE (Stephens and Donnelly 2003), as implemented in DnaSP v. 5.0 (Librado and Rozas 2009). Because the manually determined haplotypes did not show a systematic bias compared to inferred haplotypes based on PHASE, we used the inferred haplotypes for estimating diversity statistics for all genes. Sequences were aligned using MUSCLE (Edgar 2004). Alignments were manually edited using BioEdit (Hall 1999).

Data analysis

We used both genome-wide SSRs and candidate gene sequences to test for associations with phenotypic trait data from the field experiment. We inferred population structure using the software program Structure (Pritchard et al. 2000) to analyze the SSR data, as described previously (Sakiroglu et al. 2010). In brief, when all 374 individual genotypes from 120 accessions were considered, the most likely true number of subpopulations $(K)$ was five, with each of the groups corresponding to biologically meaningful divisions. The three subspecies clearly separated into distinct clusters, and the subspecies falcata and caerulea were each further divided into two subgroups. However, among the subset of 72 genotypes selected for candidate gene association, the optimum number of subpopulations $(K)$ was found to be three (Fig. 3), each corresponding to one of the subspecies (data not shown). Hence, in the association analyses of SSRs, we used $K=5$ (Sakiroglu et al. 2010) whereas for association analyses of candidate genes we used $K=3$. SPAGeDi 1.2 software (Hardy and Vekemans 2002) was used to estimate a kinship matrix for each pair of genotypes (Ritland 1996) using the 89 SSR loci. Negative kinship values were set to zero, following Yu et al. (2006).

Linkage disequilibrium among SSR markers was determined using the software program GENEPOP 4.0 (Raymond and Rousset 1995), using pairs of loci that were located on the same chromosome based on the M. truncatula genome sequence (Fig. 4). The LD between polymorphic sites within the four candidate genes was estimated using TASSEL 3.0 (Bradbury et al. 2007). Because we used a very high number of tests while calculating LD among SSR markers, corrections for multiple testing were performed using the positive false discovery rate (FDR) method (Storey 2002; Storey and Tibshirani 2003) implemented in the software program $Q$ Value (Storey 2002).

To estimate genetic diversity in the four candidate genes, we computed the average number of nucleotide differences between sequence pairs, heterozygozity per nucleotide site $(\pi)$, Tajima's $D$ statistic (Nei 1987; Tajima 1989), and Watterson's estimator of the population mutation rate $(\theta)$ (Watterson, 1975) using the computer program DnaSP v5 (Librado and Rozas 2009). DnaSP does not recognize DNA ambiguity codes. Each individual genotypic sequence resulted in two inferred haplotypic sequences from each individual.

Least square means of 23 phenotypic traits were obtained as described previously (Sakiroglu et al. 2011). 
Fig. 3 Determining optimal value of $K$ using the ad hoc procedure described by Pritchard et al. (2000) for 374 genotypes from 120 accessions (blue) and for a sub set of 72 accessions (red) (colour figure online)

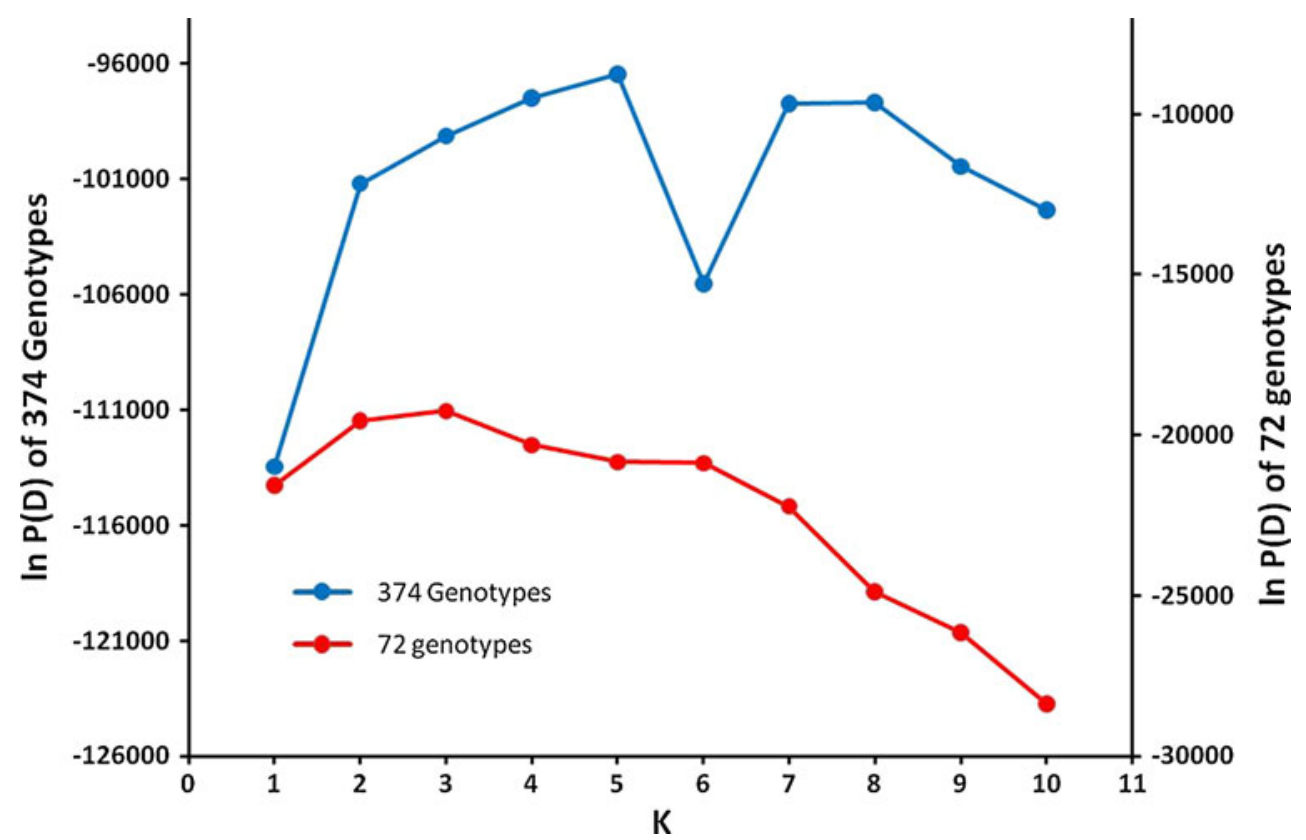

The software program TASSEL 2.1 (Bradbury et al. 2007) was used to detect associations between SSR markers and the phenotypic means. TASSEL 3.0 (Bradbury et al. 2007) was used to test for associations between candidate gene SNPs and the phenotypic means. A mixed linear model (MLM) was fitted for each single marker and trait (Yu et al. 2006). In addition to the population structure inference ( $Q$ matrix), this approach accounts for relatedness among individuals using the pairwise kinship matrix as a covariate in the mixed model. Correction for multiple testing was applied to $P$ values obtained from MLM using the positive FDR method (Storey 2002; Storey and Tibshirani 2003) implemented in software program $Q$ Value (Storey 2002). We also constructed quantile-quantile (QQ) plots to visualize the observed MLM $P$ value versus expected $P$ value distribution for each of the candidate gene association tests. Deviations from the line of equality imply an association.

Alignments for each gene region have been deposited at GenBank with the following accession numbers. F5H exon 1 JN705257-JN705321; F5H exon 2 JN714201-JN714257; PAL 1 exon 1 JN849691-JN849757; PAL 1 exon 2 JN8497 58-JN849828; COMT exon 1 JN849829-JN849897; COMT contig 2 JN849970-JN850038; CCoAoMT JN849898JN849969.

\section{Results}

Sequencing results and molecular diversity of subspecies

A total of 370,779 reads with an average length of $453 \mathrm{bp}$ was generated from the tagged amplicon library of four candidate genes. One hundred and sixteen of 1,152 total amplicons were missing or lacked sufficient coverage for further analysis. Thus, the range of read coverage for each contig was from 0 to over 2,000 (Table 1). In general missing amplicons were not clustered within one individual, however, there were three exceptions; one individual from subspecies caerulea (PI 631922) and one from subspecies hemicycla (PI 631814) were missing eight of the 16 amplicons while one individual from subspecies falcata (PI 577558) was missing seven of 16 amplicons. COMT contig 2 had the highest level of missing data. Three individuals lacked suitable read coverage for COMT contig 2 to be included in any analyses and 27 individuals were missing one of the three amplicons.

Alignments of genotype sequences across the seven contigs yielded 194 SNPs with minimum allele frequencies (MAF) above 0.05 (Table 1, Fig. 5). F5H exon 2 had the greatest number of SNPs per bp (1 SNP for every $15 \mathrm{bp}$ ) as well as the highest number of SNPs resulting in nonsynonymous substitutions (5 SNPs). CCOAoMT and COMT contig 2 are the only contigs that include introns and indels. CCoAoMT had nine indels. COMT contig 2 had only one indel.

We estimated molecular genetic diversity parameters from the inferred haplotype sequences of the four candidate genes. Overall measures of the expected heterozygosity per nucleotide site $(\pi)$ ranged from 0.008 (PAL1 exon 2) to 0.0257 ( $F 5 H$ exon 2 ) with an average of 0.0122 . The number of polymorphic sites per gene corrected for sample size, $\theta$, ranged from 0.0097 ( $\mathrm{Pal} 1$ exon 2) to 0.0197 ( $F 5 H$ exon 2 ) with an average of 0.0142 (Table 2). Since $\theta$ estimates roughly correspond to heterozygosity, our results suggest that the gene sequences from two randomly chosen wild alfalfa accessions would differ on average once every 71 

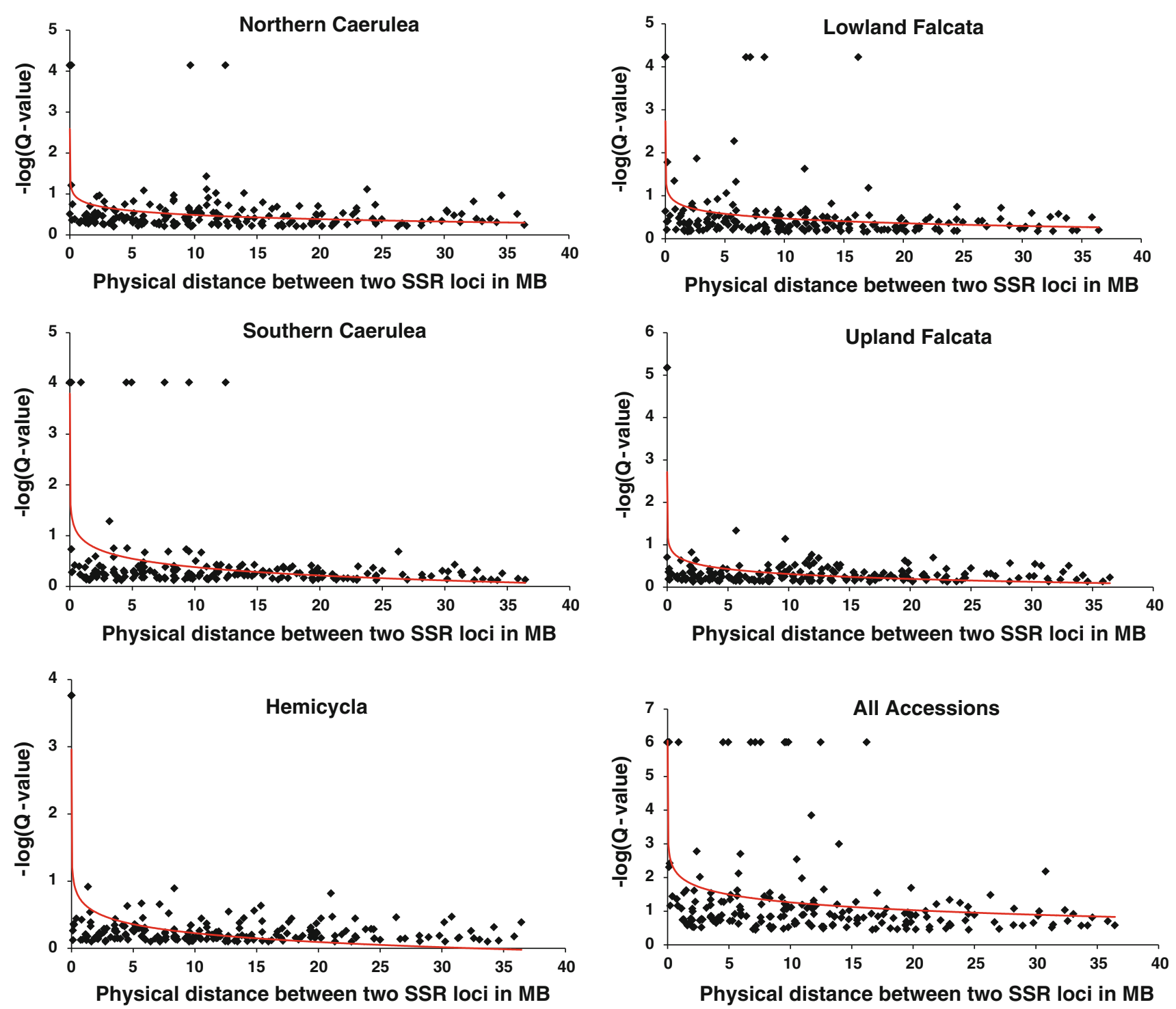

Fig. 4 Plots of linkage disequilibrium ( $-\log (Q$ value $))$ between SSR locus pairs on the same chromosome against their physical distance in Mb, based on the M. truncatula genome sequence, in five diploid alfalfa populations and over all 120 accessions

Table 1 Candidate gene amplicon composition, coverage and SNP (MAF > 0.05) distribution

\begin{tabular}{llllllll}
\hline Contig & $\begin{array}{l}\text { Number } \\
\text { of amplicons }\end{array}$ & $\begin{array}{l}\text { Alignment } \\
\text { length (bp) }\end{array}$ & $\begin{array}{l}\text { Coverage } \\
\text { range (reads) }\end{array}$ & $\begin{array}{l}\text { No. of } \\
\text { SNPs }\end{array}$ & $\begin{array}{l}\text { No. of SNPs } \\
\text { per bp }\end{array}$ & $\begin{array}{l}\text { No. of } \\
\text { NS SNPs }\end{array}$ & $\begin{array}{l}\text { No. of } \\
\text { indels }\end{array}$ \\
\hline CCoAoMT & 4 & 1,185 & $0-1,886$ & 31 & $1: 38$ & 3 & 9 \\
F5H exon 1 & 2 & 723 & $0-1,499$ & 16 & $1: 45$ & 3 & 0 \\
F5H exon 2 & 1 & 594 & $0-287$ & 39 & $1: 15$ & 5 & 0 \\
PAL1 exon 1 & 1 & 377 & $0-207$ & 14 & $1: 30$ & 1 & 0 \\
PAL1 exon 2 & 4 & 1,481 & $0-2,014$ & 52 & $1: 28$ & 0 & 0 \\
COMT exon 1 & 1 & 415 & $0-1,182$ & 11 & $1: 38$ & 2 & 0 \\
COMT contig 2 & 3 & 1,224 & $0-1,536$ & 31 & $1: 39$ & 0 & 1 \\
\hline
\end{tabular}

bases (i.e., 1/0.0142). $F 5 H$ exon 2 had the highest number of polymorphic sites, despite being one of the shortest contigs and therefore was the most diverse contig based on both of the molecular diversity parameters evaluated here.
Tajima's test of neutrality was significant in $\mathrm{F} 5 \mathrm{H}$ exon 2 for subspecies hemicycla. Despite having low sequence diversity in COMT contig 2, Tajima's test of neutrality was also significant for COMT contig 2 in subspecies falcata 


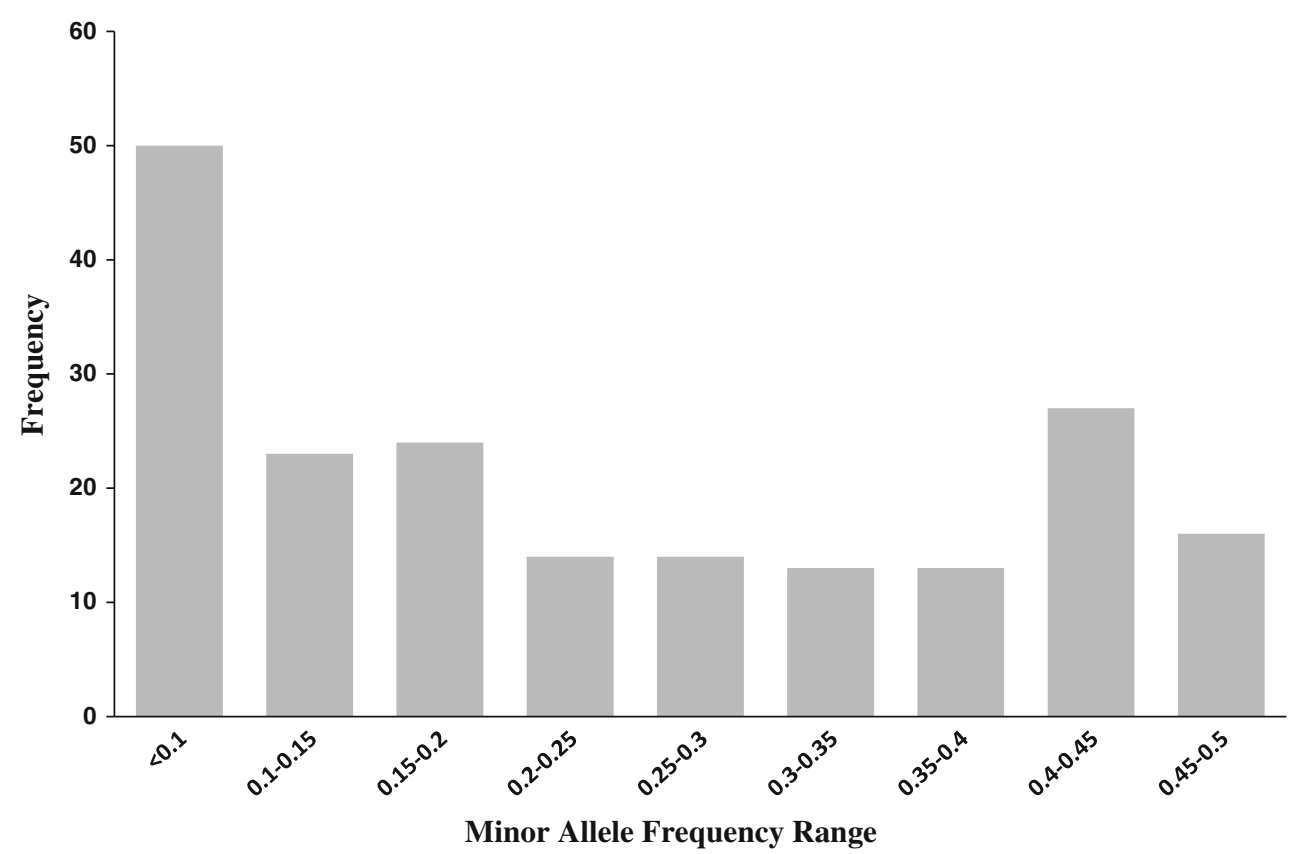

Fig. 5 Minor allele frequencies of 194 SNP discovered in seven contigs of the four candidate genes sequenced

(Table 2). Negative values of $D$ indicate an excess of rare alleles.

\section{Linkage disequilibria}

Physical locations of 58 of 89 SSR loci were identified using the $M$. truncatula genome sequence build (version 3.5.1), which covers about $66 \%$ of the gene space (Chris Town, pers. comm.). We could estimate LD from 199 locus pairs between markers known to be located on the same chromosome (Fig. 1). Markers on M. truncatula chromosomes 4 and 8 that are denoted in Fig. 1 by asterisks are most likely found on the other chromosome in $M$. sativa, because the sequenced $M$. truncatula accession has an unusual translocation between chromosomes 4 and 8 (Kamphuis et al. 2007). To investigate the evidence of the translocation in depth, we calculated LD among SSR markers that are denoted in Fig. 1 by asterisks with remaining markers of both chromosomes 4 and 8 separately. We observed only two significant associations when all accessions were considered: SSR marker BE321117 showed significant LD with al367160 on chromosome 4 and with aw267840 on chromosome 8 (Fig. 1). However, when the five groups identified by Structure were analyzed separately, no significant LD was detected, suggesting the observed LD was created by family structure rather than a real physical proximity. We excluded a total of 20 pairwise LD calculations because we could not infer the accurate distance between markers in the abovementioned situation.
The average pairwise distance between the 179 SSR marker pairs was 11.9 Mbp. We found little LD among SSR markers. To allow better visualization, we converted $P$ values of marker pairs that showed LD to $-\log$ ( $P$ value) (Fig. 4). If we consider $P$ values of 0.0001 or lower [i.e., a $-\log (P$ value $) \geq 4$ ] to indicate true LD, then we conclude that, in general, LD decays very quickly. Disregarding the five groups previously detected (Sakiroglu et al. 2010), 15 cases of LD (8.4\%) extending as long as $20 \mathrm{Mb}$ were observed-although at least some of these were probably due to population structure (Fig. 4). When the five groups were analyzed separately, the number of SSR locus pairs in LD in each group was reduced compared to the overall number of associations. Only one SSR locus pair was in LD in hemicycla, corresponding to $0.56 \%$, possibly a function of small population size. Although upland falcata and southern caerulea had the same number of individuals, the number of SSR locus pairs in LD was five times higher in southern caerulea (5.6\%) compared to upland falcata $(1.1 \%)$ (Table 3$)$.

The extent of LD varied among the candidate gene sequences (Fig. 6). Linkage disequilibrium decayed below $r^{2}=0.1$ within $750 \mathrm{bp}$ in three of the seven contigs. In CCoAoMT and PAL 1 exon 2, LD decayed rapidly to below $r^{2}=0.1$ within $500 \mathrm{bp}$. In PAL 1 exon 1 , LD decayed to an $r^{2}=0.14$ in the 377 bp length of the sequence. For $F 5 H$ exon 1 , LD did not decay below $r^{2}=0.2$ within the $723 \mathrm{bp}$ length, although the trend showed a decrease in LD with increased distance. COMT contig 2 had an average $r^{2}=0.17$ and LD did not decay across the $1,203 \mathrm{bp}$ region. 
Table 2 Summary of DNA sequence variation from four candidate genes in three subspecies of diploid alfalfa from inferred haplotypes

\begin{tabular}{|c|c|c|c|c|c|c|c|}
\hline $\begin{array}{l}\text { Medicago sativa } \\
\text { subspecies }\end{array}$ & $\begin{array}{l}\text { No. of } \\
\text { individuals }\end{array}$ & $\begin{array}{l}\text { No. of } \\
\text { polymorphic } \\
\text { sites }\end{array}$ & $\pi$ & $\theta$ & Tajima's $D$ & $\begin{array}{l}\text { No. of } \\
\text { haplotypes }\end{array}$ & $\begin{array}{l}\text { Haplotype } \\
\text { diversity (SD) }\end{array}$ \\
\hline \multicolumn{8}{|c|}{ ССоАоМT (1,340 bp) } \\
\hline caerulea & 26 & 14 & 0.0122 & 0.0115 & 0.176 & 22 & $0.911(0.025)$ \\
\hline falcata & 36 & 20 & 0.0127 & 0.0148 & -0.438 & 25 & $0.844(0.026)$ \\
\hline hemicycla & 10 & 11 & 0.0127 & 0.0117 & 0.331 & 10 & $0.926(0.032)$ \\
\hline Overall & 72 & 21 & 0.0116 & 0.0158 & -0.750 & 42 & $0.915(0.012)$ \\
\hline \multicolumn{8}{|c|}{$F 5 H$ exon 1 (723 bp) } \\
\hline caerulea & 23 & 21 & 0.0056 & 0.0068 & -0.491 & 19 & $0.804(0.058)$ \\
\hline falcata & 33 & 39 & 0.008 & 0.012 & -1.069 & 32 & $0.909(0.027)$ \\
\hline hemicycla & 9 & 16 & 0.0065 & 0.0064 & 0.004 & 6 & $0.850(0.006)$ \\
\hline Overall & 65 & 52 & 0.0095 & 0.0137 & -0.956 & 54 & $0.926(0.015)$ \\
\hline \multicolumn{8}{|c|}{$F 5 H$ exon $2(594 \mathrm{bp})$} \\
\hline caerulea & 21 & 42 & 0.0141 & 0.017 & -0.641 & 16 & $0.785(0.063)$ \\
\hline falcata & 28 & 52 & 0.0201 & 0.0202 & 0.005 & 30 & $0.901(0.034)$ \\
\hline hemicycla & 8 & 30 & 0.0085 & 0.0162 & $-1.981^{\mathrm{a}}$ & 6 & $0.617(0.135)$ \\
\hline Overall & 57 & 57 & 0.0257 & 0.0197 & 0.971 & 47 & $0.904(0.020)$ \\
\hline \multicolumn{8}{|c|}{ PAL1 exon 1 (377 bp) } \\
\hline caerulea & 25 & 24 & 0.0143 & 0.0146 & -0.129 & 16 & $0.847(0.38)$ \\
\hline falcata & 33 & 19 & 0.0109 & 0.0123 & -0.350 & 26 & $0.943(0.012)$ \\
\hline hemicycla & 9 & 14 & 0.0114 & 0.0116 & 0.058 & 12 & $0.922(0.051)$ \\
\hline Overall & 67 & 33 & 0.0143 & 0.018 & -0.620 & 43 & $0.945(0.008)$ \\
\hline \multicolumn{8}{|c|}{$P A L 1$ exon $2(1,483 \mathrm{bp})$} \\
\hline caerulea & 25 & 21 & 0.0048 & 0.007 & -1.035 & 19 & $0.780(0.06)$ \\
\hline falcata & 35 & 38 & 0.0121 & 0.0108 & 0.405 & 54 & $0.991(0.004)$ \\
\hline hemicycla & 9 & 36 & 0.0069 & 0.011 & -1.686 & 13 & $0.954(0.034)$ \\
\hline Overall & 69 & 22 & 0.0075 & 0.0097 & -0.645 & 37 & $0.853(0.025)$ \\
\hline \multicolumn{8}{|c|}{$C O M T$ exon 1 (415 bp) } \\
\hline caerulea & 26 & 15 & 0.0082 & 0.0085 & -0.136 & 11 & $0.732(0.056)$ \\
\hline falcata & 34 & 21 & 0.0101 & 0.0111 & -0.285 & 19 & $0.802(0.046)$ \\
\hline hemicycla & 9 & 11 & 0.0066 & 0.008 & -0.801 & 8 & $0.83(0.064)$ \\
\hline Overall & 69 & 26 & 0.0094 & 0.0118 & -0.597 & 29 & $0.870(0.018)$ \\
\hline \multicolumn{8}{|c|}{ COMT contig 2 (1,203 bp) } \\
\hline caerulea & 14 & 29 & 0.0068 & 0.0063 & 0.254 & 18 & $0.918(0.044)$ \\
\hline falcata & 23 & 45 & 0.0038 & 0.0089 & $-2.123^{\mathrm{a}}$ & 22 & $0.84(0.051)$ \\
\hline hemicycla & 5 & 44 & 0.0121 & 0.0143 & -0.741 & 9 & $0.978(0.054)$ \\
\hline Overall & 42 & 62 & 0.0071 & 0.0108 & -1.336 & 45 & $0.933(0.019)$ \\
\hline Average Overall & & & 0.0122 & 0.0142 & & & \\
\hline
\end{tabular}

a Tajima's $D$ values significantly deviated from zero $(\mathrm{p}<0.05)$

LD was highest in $F 5 H$ exon 2 with an average $r^{2}=0.33$ and did not decay. The pattern of linkage disequilibrium in $\mathrm{F} 5 \mathrm{H}$ exon 2 for each subspecies indicates that linkage disequilibrium was strongest in subspecies hemicycla (Supplementary Figure 1). COMT contig 2 and $F 5 H$ exon 2 had significant values for Tajima's $D$ in subspecies falcata and hemicycla, respectively (Table 2).
Tests of association

Based on genomewide association analysis with 89 SSR loci and 23 phenotypic traits, we found only one weak association (FDR $Q$ value $=0.037$ ) with total biomass yield in 2007 (Table 4). The SSR marker mticl4 is located on Chromosome 6 according to the $M$. truncatula genome sequence 
Table 3 Number of SSR locus pairs showing linkage disequilibrium in five main populations of diploid alfalfa and over all genotypes based on a significance level of $P=0.0001$ after control for the false discovery rate (FDR)

\begin{tabular}{lcll}
\hline Groups & $\begin{array}{l}\text { No. of } \\
\text { genotypes }\end{array}$ & $\begin{array}{l}\text { No. of } \\
\text { locus pairs } \\
\text { in LD }\end{array}$ & $\begin{array}{l}\text { \% of } \\
\text { locus pairs } \\
\text { in LD }\end{array}$ \\
\hline Southern caerulea & 99 & 10 & 5.6 \\
Northern caerulea & 69 & 5 & 2.8 \\
Hemicycla & 44 & 1 & 0.56 \\
Lowland falcata & 63 & 6 & 1.3 \\
Upland falcata & 99 & 2 & 1.1 \\
Overall & 374 & 15 & 1.8 \\
\hline
\end{tabular}

build 3.5; however, it had previously been mapped to linkage group 2 in alfalfa (Robins et al. 2007). The marker did not show any LD with the other SSR loci known to be located on chromosomes 2 or 6 .

Tests of association between 194 SNPs with a minimum allele frequency $(\mathrm{MAF})>0.05$ from the four candidate genes with 23 phenotypic traits resulted in seven significant associations with FDR $Q$ values $<0.05$ (Table 4). Additional SNP-trait associations with $P$ values $<0.05$ but that were not significant after correcting for multiple testing are listed in Supplemental Table 4. Only two SNP-phenotype associations were identified when quantile-quantile (QQ) graphs were plotted (Supplementary Figure 2). One marker,
SNP 111 in CCoAoMT, was associated with total biomass yield in both 2007 and 2008, stem proportion in 2007, and stem thickness in 2008. CCoAoMT SNP 111 is located in the first intron (Fig. 2) and not linked to any other SNPs. Increased yield in 2007 was associated with the $\mathrm{C} / \mathrm{T}$ genotype at position 111 . Only five individuals of $61(8 \%)$ for which we had sufficient sequence coverage had a thymine at that position, including four $M$. sativa subsp. caerulea and one $M$. sativa subsp. falcata genotypes (Fig. 7a). A SNP in $F 5 H$ exon 2 was associated with yield in 2008 . The SNP at position 276 is a synonymous substitution (Fig. 2). The highest yield values were associated with the homozygous TT condition found in ten of 56 individuals (Fig. 7b). Another SNP in CCoAoMT was associated with regrowth in 2007.

\section{Discussion}

Candidate gene sequencing and sequence diversity

For sequencing in this project, we multiplexed four genes consisting of seven contigs derived from 16 overlapping tagged amplicons and aimed for $600 \times$ coverage using Titanium chemistry on the 454 FLX sequencer. Our amplicon lengths were approximately $500 \mathrm{bp}$, but we were not certain about the read lengths we could expect from the Titanium chemistry when we started the experiment. We were also

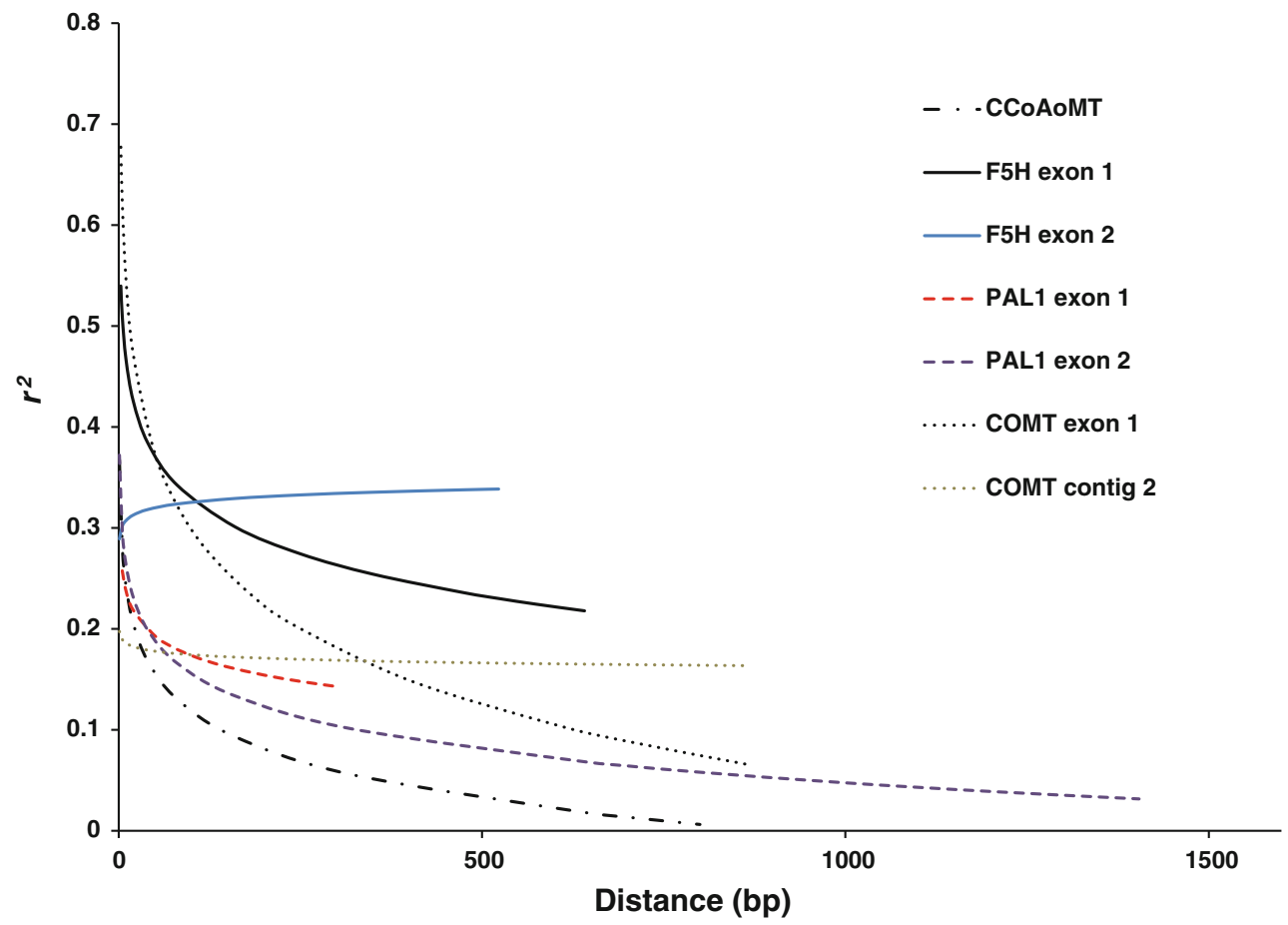

Fig. 6 LD plots of squared correlations of allele frequencies $\left(r^{2}\right)$ against distance between polymorphic sites for four candidate genes in seven contigs as depicted in Fig. 2 
Table 4 Significant markerphenotype associations after correction for multiple testing using the positive FDR method. (SNP FDR $Q$ values $<0.05$ ) ported by QQ plots

\begin{tabular}{|c|c|c|c|c|c|c|c|}
\hline \multirow[t]{2}{*}{ Trait } & \multirow[t]{2}{*}{ Year } & \multirow{2}{*}{$\begin{array}{l}\text { Marker/ } \\
\text { position }\end{array}$} & \multirow{2}{*}{$\begin{array}{l}\text { Linkage } \\
\text { group }\end{array}$} & \multirow[t]{2}{*}{$F$} & \multicolumn{2}{|c|}{ Marker effect } & \multirow{2}{*}{$\begin{array}{l}\text { FDR } \\
Q \text { value }\end{array}$} \\
\hline & & & & & $P$ & $r^{2}$ & \\
\hline Yield & 2007 & ССОАОМТ/111 & 4 & 21.96 & $8.50 \mathrm{E}-08$ & $8.50 \mathrm{E}-08$ & $5.64 \mathrm{E}-05^{\mathrm{a}}$ \\
\hline Stem proportion & 2007 & ССОАОМТ/111 & 4 & 15.01 & $5.78 \mathrm{E}-06$ & $5.78 \mathrm{E}-06$ & 0.0013 \\
\hline Yield & 2008 & ССОАОМТ/111 & 4 & 17.77 & $1.01 \mathrm{E}-06$ & $1.01 \mathrm{E}-06$ & 0.0003 \\
\hline Stem thickness & 2008 & ССОАОМТ/111 & 4 & 8.91 & $4.31 \mathrm{E}-04$ & $4.31 \mathrm{E}-04$ & 0.0476 \\
\hline Regrowth & 2007 & ССОАОМТ/1006 & 4 & 9.65 & $2.32 \mathrm{E}-04$ & $2.32 \mathrm{E}-04$ & 0.0308 \\
\hline Yield & 2008 & $F 5 H$ exon $2 / 276$ & 5 & 10.74 & $1.55 \mathrm{E}-05$ & 0.5682 & $0.0094^{\mathrm{a}}$ \\
\hline Yield & 2008 & SSR, MTIC14 & 6 & 2.8 & $4.71 \mathrm{E}-05$ & & 0.037 \\
\hline
\end{tabular}

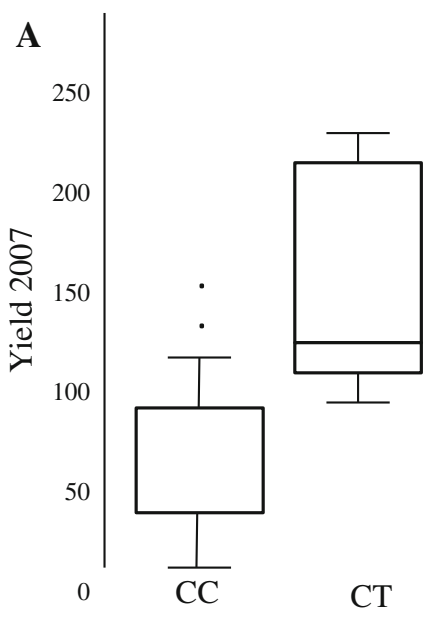

$\begin{array}{lrr}\text { M. } \text { s. } \text { hemicycla } & 9 & 0 \\ \text { M. s. } \text { caerulea } & 19 & 4 \\ \text { M. s. falcata } & 28 & 1 \\ \text { all subspecies } & 92 \% & 8 \%\end{array}$

Fig. 7 Significant SNP-trait associations (a) CCoAoMT SNP 111 and yield 2007. Phenotypic effects of genotypes at position 111. Percentage of individuals sampled with each genotypic class for each subspecies and overall subspecies. b Significant SNP-trait association

concerned that our estimation of the concentrations of the 1,200 amplicon reactions was accurate. Taken together, this uncertainty supported our conservative approach. Our experience from this study indicates that accurate haplotype deduction can be achieved with as few as 35454 FLX reads because, at this coverage level, sequencing errors can still be easily distinguished from true SNPs. The advantages of 454 sequencing over Sanger and Illumina methods are that read lengths allow for the determination of phase over longer distances and insertion-deletion mutations can be easily deduced, both of which are useful for distinguishing haplotypes. Template concentration for PCR, amplicon quantification for pooling prior to sequencing, and methods to avoid PCR recombination which we encountered and that has been seen by other groups (Griffin et al. 2011) are all needed to ensure even coverage of 35-100X.

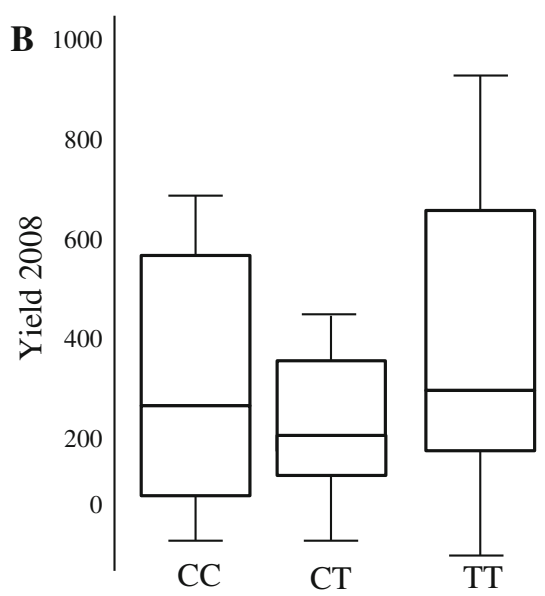

$\begin{array}{lrrr}\text { M. s. } \text { hemicycla } & 1 & 1 & 4 \\ \text { M. s. caerulea } & 6 & 5 & 8 \\ \text { M. s. falcata } & 27 & 1 & 0 \\ \text { all subspecies } & 63 \% & 15 \% & 22 \%\end{array}$

between $F 5 H$ exon 2 SNP 276 and yield 2008. Phenotypic effects of genotypes at position 276. Percentage of individuals sampled with each genotypic class for each subspecies and overall subspecies

A previous study investigating the history of domestication of alfalfa (Muller et al. 2005) reported higher levels of sequence diversity for diploid $M$. sativa subsp. caerulea than we report here. Sequence diversity at two genes sampled from eight individuals resulted in $\theta=0.0376$ and $\theta=0.0272$ while our values ranged from 0.0048 to 0.0143 . The strategy used by Muller et al. (2005) was very different from ours in a few ways. First, only one allele per individual was used in an effort to sample more variation across a diverse collection of Medicago. Second, the plant material used in their study included diploid and tetraploid, domesticated, and wild populations. Finally, their sequences were from predominantly intron regions.

Comparing patterns of genetic diversity across species could be hampered due to differences in the mode of reproduction (self pollinated vs. cross pollinated) and the nature 
of genetic material used (breeding material vs. unimproved population). Alfalfa has a predominantly outcrossing breeding system and the plant material used in this experiment is unimproved germplasm collected from broad-based populations. Although we observed higher sequence diversity in the four candidate genes compared to other crop species and model plants (Tenaillon et al. 2001; Schmid et al. 2005; Liu and Burke 2006; Mather et al. 2007), we focused on comparing our results to the wild relatives or landraces of maize (Zea mays ssp. mays L.) and sunflower (Helianthus annииs L.), which are also outcrossing populations and could be assumed to be more similar to alfalfa than populations from autogamous species. The average $\theta$ value estimated in this study (0.0142) was comparable to the values from 21 genes in 15 maize landraces $(\theta=0.0129$; Tenaillon et al. 2001) and from nine genes in 16 wild populations of sunflower $(\theta=0.0144$; Liu and Burke 2006).

Tajima's test of neutrality indicated that selection may be acting on $F 5 H$ exon 2 within subspecies hemicycla, but not in the other subspecies. Sliding window analysis of $\mathrm{F} 5 \mathrm{H}$ exon 2 did not detect significant values for Tajima's $D$ within subspecies caerulea or falcata, but Tajima's $D$ was consistently negative for hemicycla. Negative Tajima's $D$ values indicate an excess of rare variation, which may be due to hemicycla's hybrid nature, consisting of genetic variation derived from both of the other subspecies. Tajima's test of neutrality is negative for COMT contig 2 in subspecies falcata, suggesting that selection has acted on this sequence.

\section{Linkage disequilibria}

The extent of LD is crucial to determine marker density necessary for association mapping analyses, with longer LD requiring fewer markers to saturate the genome, but resulting in lower resolution (Jorde 1995; Buckler and Thornsberry 2002; Ching et al. 2002; Rafalski and Morgante 2004). We observed very little LD between SSR marker pairs and the estimates of the extent of LD in our study are lower than those reported in maize and barley (Remington et al. 2001; Liu et al. 2003; Stich et al. 2005; Malysheva-Otto et al. 2006). The small number of SSR locus pairs in LD could partially be due to the FDR calculations that we used to correct possible false positives arising from thousands of pairwise LD calculations. It could also be due to the nature of the plant material. In the above-mentioned studies, landraces or inbred lines that had resulted from human selection were used, which could create LD (Jannink and Walsh 2002), whereas our germplasm contained all wild accessions. The extent of LD in alfalfa was previously estimated in a breeding population using SSR markers and the results revealed that $61.5 \%$ of SSR marker pairs separated by less than $1 \mathrm{Mbp}$ were in $\operatorname{LD}(P<0.001)$ implying extensive LD ( $\mathrm{Li}$ et al. 2011). However, Li et al. (2011) used a synthetic tetraploid alfalfa population that was derived from 300 individuals of three cultivars (100 individuals from each cultivar). The larger estimate of the extent of LD obtained by Li et al. (2011) compared to LD in our study was probably due to artificial selection.

LD is considered to have decayed when $r^{2}$ values drop below 0.1 (Remington et al. 2001, Ersoz et al. 2007). Two of our gene sequences decayed below $r^{2}=0.1$ in $500 \mathrm{bp}$ and overall LD was below 0.2 within 500 bp in five of the seven contigs. Only $F 5 H$ exon 2 compares to a previous report of within gene LD in alfalfa. Estimates of within gene LD in a CONSTANS-LIKE gene from 59 genotypes of a breeding variety in tetraploid alfalfa revealed that $L D$ of $r^{2}=0.2$ could persist as long as $700 \mathrm{bp}$ (Herrmann et al. 2010). The difference between the LD estimates in two studies is probably attributed to usage of different genetic material. Herrmann et al. (2010) used cultivated material in which LD could persist over longer distances due to bottlenecks produced by artificial selection (Ching et al. 2002; Liu and Burke 2006; Kolkman et al. 2007), where as we used broad-based wild germplasm. The difference in the extent of LD between different genetic materials has previously been reported in other crops (Caldwell et al. 2006; Liu and Burke 2006).

Association analyses

We identified one SSR marker, and three SNPs associated with biomass yield, stem proportions, regrowth, and stem thickness but no associations with cell wall composition traits. Given the relative paucity of SSR markers we examined and the limited number of individuals (and few genes) in our candidate gene analysis, this lack of association is not surprising. The CCoAoMT SNP in position of 111 associated with several traits is located in the first intron and although it is not in linkage disequilibrium with any SNPs in the first exon or downstream of this site, it may be linked to causative SNPs in the promoter region. The $F 5 H$ exon 2 SNP associated with yield in 2008 is a synonymous change; however, LD does not decay within the region we sequenced, so this SNP may be linked functionally to an unsampled causative SNP. The nature of each of these associations needs to be investigated further and validated in additional alfalfa populations.

Successful candidate gene association mapping studies have generally focused on genes from single pathways (Myles et al. 2009). Despite evidence that the lignin biosynthetic genes $C C O A o M T$ and $F 5 H$ directly impact the lignin content of alfalfa (Guo et al. 2001; Chen and Dixon 2007), our candidate gene approach did not detect any associations with the cell wall characteristics measured, which were based on fiber analysis. Weak associations between 
lignin genes and both yield traits and cell wall components have been reported previously from maize inbred lines by Chen et al. (2010), who concluded that qualitative trait polymorphisms for yield and cell wall characteristics segregate independently of one another. The phenylpropanoid pathway, of which lignin is one of many products, has several components that have been linked to plant growth.

In summary, in this paper we attempt to estimate both genome-wide SSR and within gene SNP variation to determine the extent of LD in diploid alfalfa. In terms of the potential to use the candidate gene approach for allele mining for alfalfa improvement, we have shown that although our sample size was small, two significant SNPs in two candidate genes that are associated with biomass yield and other traits were detected.

Acknowledgments This research was supported by United States Department of Agriculture-Department of Energy Plant Feedstock Genomics for Bioenergy award 2006-35300-17224 to E. Charles Brummer.

Open Access This article is distributed under the terms of the Creative Commons Attribution License which permits any use, distribution, and reproduction in any medium, provided the original author(s) and the source are credited.

\section{References}

Aranzana MJ, Kim S, Zhao K et al (2005) Genome-wide association mapping in Arabidopsis identifies previously known flowering time and pathogen resistance genes. PLoS Genet 1:531-539

Bradbury PJ, Zhang Z, Kroon DE et al (2007) TASSEL: software for association mapping of complex traits in diverse samples. Bioinformatics 23:2633-2635

Buckler ES, Thornsberry JM (2002) Plant molecular diversity and applications to genomics. Curr Opin Plant Biol 5:107-111

Caldwell KS, Russell J, Langridge P, Powell W (2006) Extreme population-dependent linkage disequilibrium detected in an inbreeding plant species, Hordeum vulgare. Genetics 172:557-567

Chen F, Dixon RA (2007) Lignin modification improves fermentable sugar yields for biofuel production. Nat Biotechnol 25:759-762

Chen Y, Zein I, Brenner E et al (2010) Polymorphisms in monolignol biosynthetic genes are associated with biomass yield and agronomic traits in European maize (Zea mays L.). BMC Plant Biol 10:12-22

Ching ADA, Caldwell K, Jung M et al (2002) SNP frequency, haplotype structure and linkage disequilibrium in elite maize inbred lines. BMC Genet 3:19-33

Delong MM, Swanberg DR, Oelke EA et al (1995) Sustainable biomass energy production and rural economic development using alfalfa as a feedstock. In: Second Biomass Conference of the Americas: Energy, Environment, Agriculture, and Industry, Portland, pp 21-24

Diwan N, Bouton JH, Kochert G, Cregan PB (2000) Mapping of simple sequence repeat (SSR) DNA markers in diploid and tetraploid alfalfa. Theor Appl Genet 101:165-172

U.S. DOE (2006) Breaking the biological barrier to cellulosic ethanol: a joint research agenda, DOE/SC-0095, U.S. Department of Energy Office of Science and Office of Energy Efficiency and Renew- able Energy. http://genomicscience.energy.gov/biofuels/b2bwork shop.shtml\#page=news. Accessed 02 Dec 2011

Edgar RC (2004) MUSCLE: multiple sequence alignment with high accuracy and high throughput. Nucleic Acids Res 32:1792

Ersoz E, Yu J, Buckler ES (2007) Applications of linkage disequilibrium and association mapping in crop plants. In: Varshney R, Tuberosa R (eds) Genomic assisted crop improvement, vol 1. Springer, Dordrecht, pp 97-120

Griffin P, Robin C, Hoffmann A (2011) A next-generation sequencing method for overcoming the multiple gene copy problem in polyploid phylogenetics, applied to Poa grasses. BMC Biol 9:19-37

Guo D, Chen F, Inoue K et al (2001) Downregulation of caffeic acid 3$O$-methyltransferase and caffeoyl CoA 3-O-methyltransferase in transgenic alfalfa: impacts on lignin structure and implications for the biosynthesis of $\mathrm{G}$ and S lignin. Plant Cell 13:73-88

Hagenblad J, Nordborg M (2002) Sequence variation and haplotype structure surrounding the flowering time locus FRI in Arabidopsis thaliana. Genetics 161:289-298

Hall T (1999) BioEdit: a user-friendly biological sequence alignment editor and analysis program for Windows 95/98/NT. Nucleic Acids Symp Ser 4:95-98

Hardy OJ, Vekemans X (2002) SPAGeDi: a versatile computer program to analyse spatial genetic structure at the individual or population levels. Mol Ecol Notes 2:618-620

Havananda T, Brummer EC, Maureira-Butler IJ, Doyle JJ (2010) Relationships among diploid members of the Medicago sativa (Fabaceae) species complex based on chloroplast and mitochondrial DNA sequences. Syst Bot 35:140-150

Herrmann D, Barre P, Santoni S, Julier B (2010) Association of a CONSTANS-LIKE gene to flowering and height in autotetraploid alfalfa. Theor Appl Genet 121:865-876

Hill RR, Shenk JS, Barnes RF (1988) Breeding for yield and quality. In: Hanson AA et al (eds) Alfalfa and alfalfa improvement. ASACSSA-SSSA, Madison, pp 809-825

Hirschhorn JN, Daly MJ (2005) Genome-wide association studies for common diseases and complex traits. Nat Rev Genet 6:95-108

Jannink JL, Walsh B (2002) Association mapping in plant populations. In: Kang MS (ed) Quantitative genetics, genomics, and plant breeding. CAB International, NY, pp 59-68

Jorde LB (1995) Linkage disequilibrium as a gene-mapping tool. Am J Hum Genet 56:11-14

Kamphuis LG, Williams AH, D'Souza NK et al (2007) The Medicago truncatula reference accession A17 has an aberrant chromosomal configuration. New Phytol 174:299-303

Kolkman JM, Berry ST, Leon AJ et al (2007) Single nucleotide polymorphisms and linkage disequilibrium in sunflower. Genetics 177:457-468

Lande R, Thompson R (1990) Efficiency of marker-assisted selection in the improvement of quantitative traits. Genetics 124:743-756

Lander ES, Schork NJ (1994) Genetic dissection of complex traits. Science 265:2037-2048

Li X, Wei Y, Moore KJ et al (2011) Association mapping of biomass yield and stem composition in a tetraploid alfalfa breeding population. Plant Genome 4:24-35

Librado P, Rozas J (2009) DnaSP v5: a software for comprehensive analysis of DNA polymorphism data. Bioinformatics 25:14511452

Liu A, Burke JM (2006) Patterns of nucleotide diversity in wild and cultivated sunflower. Genetics 173:321-330

Liu KJ, Goodman M, Muse S, Smith JS, Buckler E, Doebley J (2003) Genetic structure and diversity among maize inbred lines as inferred from DNA microsatellites. Genetics 165:2117-2128

Mackay I, Powell W (2007) Methods for linkage disequilibrium mapping in crops. Trends Plant Sci 12:57-63

Malysheva-Otto L, Ganal M, Röder M (2006) Analysis of molecular diversity, population structure and linkage disequilibrium in a 
worldwide survey of cultivated barley germplasm (Hordeum vulgare L.). BMC Genet 7:6-20

Mather KA, Caicedo AL, Polato NR et al (2007) The extent of linkage disequilibrium in rice (Oryza sativa L.). Genetics 177:2223-2232

McCoy TJ, Bingham ET (1988) Cytology and cytogenetics of alfalfa. In: Hanson AA et al (eds) Alfalfa and alfalfa improvement. ASACSSA-SSSA, Madison, pp 737-776

Meyer M, Stenzel U, Hofreiter M (2008) Parallel tagged sequencing on the 454 platform. Nat Protoc 3:267-278

Michaud E, Leman WF, Rumbaugh MD (1988) World distribution and historical development. In: Hanson AA et al (eds) Alfalfa and alfalfa improvement. ASA-CSSA-SSSA, Madison, pp 25-92

Muller MH, Poncet C, Prosperi M, Santoni S, Ronfort J (2005) Domestication history of Medicago sativa species complex: inferences from nuclear sequence polymorphism. Mol Ecol 15:1589-1602

Myles S, Peiffer J, Brown PJ et al (2009) Association mapping: critical considerations shift from genotyping to experimental design. Plant Cell 21:2194-2202

Neale DB, Savolainen O (2004) Association genetics of complex traits in conifers. Trends Plant Sci 9:325-330

Nei M (1987) Molecular evolutionary genetics. Columbia University Press, New York

Oraguzie NC, Rikkerink EHA, Gardiner SE, Silva HN (2007) Association mapping in plants. Springer, NY

Pritchard JK, Stephens M, Donnelly P (2000) Inference of population structure using multilocus genotype data. Genetics 155:945-959

Quiros CF, Bauchan GR (1988) The genus Medicago and the origin of the Medicago sativa complex. In: Hanson AA et al. (eds) Alfalfa and alfalfa improvement, ASA-CSSA-SSSA, Madison, pp 93 124

Rafalski A, Morgante M (2004) Corn and humans: recombination and linkage disequilibrium in two genomes of similar size. Trends Genet 20:103-111

Ragauskas AJ, Williams CK, Davison BH et al (2006) The path forward for biofuels and biomaterials. Science 311:484-489

Raymond M, Rousset F (1995) GENEPOP (version 1.2): population genetics software for exact tests and ecumenicism. J Hered $86: 248-249$

Remington DL, Thornsberry JM, Matsuoka Y et al (2001) Structure of linkage disequilibrium and phenotypic associations in the maize genome. PNAS 98:11479-11484

Ritland K (1996) Estimators for pairwise relatedness and individual inbreeding coefficients. Genet Res 67:175-185
Robins JG, Bauchan GR, Brummer EC (2007) Genetic mapping forage yield, plant height, and regrowth at multiple harvests in tetraploid alfalfa (Medicago sativa L.). Crop Sci 47:11-18

Sakiroglu M, Brummer EC (2011) Clarifying the ploidy of some accessions in the USDA alfalfa germplasm collection. Turk J Bot 35:509-519

Sakiroglu M, Doyle JJ, Brummer EC (2010) Inferring population structure and genetic diversity of broad range of wild diploid alfalfa (Medicago sativa L.) accessions using SSR markers. Theor Appl Genet 121:403-415

Sakiroglu M, Moore KJ, Brummer EC (2011) Variation in biomass yield, cell wall components, and agronomic traits in a broad range of diploid alfalfa accessions. Crop Sci 51:1956-1964

Schmid KJ, Ramos-Onsins S, Ringys-Beckstein H et al (2005) A multilocus sequence survey in Arabidopsis thaliana reveals a genome-wide departure from a neutral model of DNA sequence polymorphism. Genetics 169:1601-1615

Stephens M, Donnelly P (2003) A comparison of bayesian methods for haplotype reconstruction from population genotype data. Am J Hum Genet 73:1162-1169

Stich B, Melchinger AE, Frisch M et al (2005) Linkage disequilibrium in European elite maize germplasm investigated with SSRs. Theor Appl Genet 111:723-730

Storey JD (2002) A direct approach to false discovery rates. J Roy Stat Soc B 64:479-498

Storey JD, Tibshirani R (2003) Statistical significance for genomewide studies. PNAS 100:9440-9445

Stuber CW, Polacco M, Senior ML (1999) Synergy of empirical breeding, marker-assisted selection, and genomics to increase crop yield potential. Crop Sci 39:1571-1583

Tajima F (1989) Statistical method for testing the neutral mutation hypothesis by DNA polymorphism. Genetics 123:585-595

Tenaillon MI, Sawkins MC, Long AD et al (2001) Patterns of DNA sequence polymorphism along chromosome 1 of maize (Zea mays ssp. mays L.). PNAS 98:9161-9166

Watterson GA (1975) On the number of segregating sites in genetical models without recombination. Theor Pop Biol 7:256-276

Yu J, Pressoir G, Briggs WH, Vroh Bi I, Yamasaki M, Doebley JF, McMullen MD, Gaut BS, Nielsen DM, Holland JB, Kresovich S, Buckler ES (2006) A unified mixed-model method for association mapping that accounts for multiple levels of relatedness. Nat Genet 38:203-208 